\title{
MODEL PENDIDIKAN SEKS PADA ANAK DI TKIP MUTIARA BATURETNO BANTUL YOGYAKARATA
}

\author{
Annisa Nur Firdausyi \\ Universitas Muhammadiyah Metro \\ firdausyiannisa@gmail.com
}

\begin{abstract}
In the study qualitative research and it is taking the background of TKIP Mutiara Baturetno Bantul Yogyakarta in Model of sex education in childern, which refers to several developments values and religion, physical motor, language, social emotional and art. With the formulation of the problem. How is the model of sex education in children in TKIP Mutiara Baturetno Bantul Yogyakarta?

This research is using a qualitative research and data collection had done by conducting the observation, interview, and documentation. Reseach approch using the phenomenology with data analysis that ut can give meaning to take the conclusion. The result of the research shows Model of sex education in Children in TKIP Mutiara Baturetno Bantul Yogyakarta there is an non directive teaching learning model, learning model of awareness training (habituation), and discussion learning model. 2) Implementation of the process of learning sex education in children the existence of support factors from all components of the school, Sex education materials in children have been adapted to 6 aspects of development in the curriculum program TKIP Mutiara. The goal of learning is to recognize God's human creation, strategies used in sexual education in children with habitual toilet training namely toilets in TKIP Mutiara already in the setting by distinguishing the men's and women's bathrooms are self-contained or made separately.
\end{abstract}

Keywords: Learning Model, Sex Education in Children

\begin{abstract}
ABSTRAK
Pada penelitian ini mengambil latar belakang TKIP Mutiara Baturetno Bantul Yogyakarta dalam Model Pendidikan Seks pada Anak yang mengacu pada beberapa perkembangan, nilai dan agama, fisik motorik, bahasa, soaial emosioanl dan seni. Dengan rumusan masalah Bagaiman Model pendidikan seks pada anak di TKIP Mutiara Baturetno Bantul Yogyakarta?

Penelitian ini merupakan penelitian kualitatif, pengumpulan data yang dilakukan dengan mengadakan observasi, wawancara dan dokumentasi. Pendekatan penelitian menggunakan fenomenologi dengan analisis data yang dapat memberikan makna untuk di ambil kesimpulan. Penelitian ini bertujuan untuk mengetahui bagaimana model pendidikan seks pada anak di TKIP Mutiara Baturetno Bantul Yogyakarta.
\end{abstract}


Hasil penelitian menunjukkan: 1) Model pendidikan seks pada Anak di TKIP Mutiara Baturetno Bantul Yogyakarta ada model pembelajaran tidak langsung, model pembelajaran pelatihan kesadaran (pembiasaan), dan model pembelajaran diskusi, 2) Pelaksanaan proses pembelajaran pendidikan seks pada anak adanya faktor-faktor dukungan dari seluruh komponen sekolah. Materi-materi pendidikan seks pada anak telah disesuaikan dengan 6 aspek perkembangan pada program kurikulum TKIP Mutiara. Tujuan pembelajarannya adalah untuk mengenal manusia ciptaan Allah .Strategi yang digunakan dalam pendidikan seksual pada anak dengan pembiasaan toilet training, yakni toilet di TKIP Mutiara sudah di setting dengan membedakan kamar mandi putra dan putri ada sendiri-sendiri atau dibuat terpisah.

Kata Kunci: Model Pembelajaran, Pendidikan Seks pada Anak

\section{A. PENDAhuluan}

Masa usia dini sering dikatakan sebagai masa keemasan atau golden age. Masa keemasan adalah masa dimana anak memiliki kemampuan penyerapan informasi yang sangat pesat. Kemajuan teknologi informatika di Indonesia disatu sisi menjadi suatu kebanggaan namun, disisi lain sebagai suatu ancaman bagi perkembangan psikologis dan sosial anak.

KPAI juga menunjukkan bahwa pelaku kekerasan adalah orang-orang terdekat korban (keluarga, sekolah dan masyarakat). Hasil monitoring KPAI jawa tengah pada tahun 2015 memiliki 1227 kasus kekerasan dan 68,8\% merupakan kasus kekerasan seksual dengan korban anak-anak. ${ }^{1}$ Menurut Komisioner KPAI (Komisi Perlindungan Anak Indonesia) Jasra Putra. Tiga tahun terakhir nampaknya menjadi tahun yang memperhatinkan bagi dunia anak Indonesia. Pasalnya Komisi KPAI menemukan ratusan kasus kekerasan seksual terhadap anak yang di duga dilakukan orang terdekat sebagai pelaku. Data menunjukan bahwa menemukan 218 kasus kekerasan seksual anak pada 2015. Sementara pada 2016, KPAI Mencatat terdapat 120 kasus kekerasan seksual terhadap anak-anak. Kemudian di tahun 2017, tercatat sebanyak 116 kasus. $^{2}$

Berdasarkan hasil survey wawancara dengan guru TKIP Mutiara Baturetno Bantul terdapat gambaran bahwa di sekitaran lingkungan sekolah belum menemukan

\footnotetext{
${ }^{1}$ Dinar Wukirsari, ,Modul “sayangi aku” untuk meningkatkan efikasi mengajar Guru TK dalam Pencegahan Kekekrasan Seksual Pada Anak, Tesis yang diterbitkan, (Yogyakarta: Program Magister Psikologi Profesi, 2017) hlm 3

${ }^{2}$ www.kpai.go.id tentang tahun 2017, KPAI temukan kasus 116 kekerasan seksual terhadap anak (Di akses pada tanggal 10 November 2017, pukul 13.00 WIB) .
} 
kekerasan seksual, akan tetapi di tempat tinggal guru menemukan kasus kekerasan seksual yang korbannya adalah anak-anak. Dari 5 guru, terdapat 2 guru mengungkapkan pernah menemui kasus kekerasan seksual pada anak. Salah satu kasus yang sedang marak terjadi yakni di sekolah bertaraf internasional, yaitu kasus pelecehan seksual yang dilakukan oleh petugas kebersihan sekolah dan guru terhadap murid Taman Kanak-Kanak Jakarta Internasional School (JIS). Seorang kakek mencabuli 10 anak di bawah umur. ${ }^{3}$ Anak laki laki yang menjadi korban kekerasan seksual lebih berpotensi untuk mengarahkan reaksi mereka secara eksternal ketika tumbuh menjadi individu laki-laki dewasa. Pendidikan seksualitas yang tidak diberikan di usia dini mengakibatan tingginya kekerasan seksual maupun pelecehan seksual pada anak yang dilakukan orang-orang terdekat termasuk keluarga. ${ }^{4}$

Dari fenomena seperti ini pendidikan seks menjadi salah satu solusi untuk mengetaskan permasalahan yang berkaitan dengan seks. Abdullah Nasih Ulwan mengemukakan bahwa pendidikan seks adalah daya tarik menarik antara satu sama lain. Sesungguhnya tidak ada batasan sejak kapan pendidikan seks dapat diberikan. pendidikan seks dapat dimulai dan diberikan ketika anak sudah mulai bertanya tentang seks (Jenis kelamin) dan kelengkapan jawaban bisa diberikan sesuai dengan seberapa jauh keingintahuan mereka dan tahapan umur sang anak. ${ }^{5}$

Kurangnya pemahaman anak tentang pelecehan dan kekerasan seksual membuat anak hanya diam dan tidak memberi tahukan orangtuanya ketika mengalami hal tersebut. Oleh karena itu, pembicaraan, bimbingan dan arahan yang berkaitan dengan seks ternyata sangatlah penting disaat masa perkembangan seksual anak. Bidang pendidikan, sekolah dan guru memiliki peran penting untuk mencegah terjadinya

\footnotetext{
${ }^{3}$ Liputan 6.com, Jakarta, Rabu 12 Juli 2017 ( diakses pada tanggal 5 Oktober 2017, pukul 23.03) memberitakan bahwa Polres Metro Jakarta Selatan menangkap tersangka ZU alias babeh, seorang kakak yang melakukan perbuatan cabul terhadap 10 anak, pelaku adalah pedagang pakain keliling, pelaku melakukanya dengan cara mengiming-imingi korbannya dengan uang Rp 20.000, setelah uang diberikan pelaku mengajak korban masuk ke dalam mobil lalu mempertontonkan video porno pada korbanya, yang rata-rata berumur 4-8 tahun

${ }^{4}$ Yahya Edi Ruswadi " Persepsi Guru, Kepala Sekolah, dan Wali Murid tentang implementasi pendidikan seksualitas di SD Negeri Bugel Bagelan Purworejo", Tesis, Fakultas Ilmu Tarbiyah dan Keguruan 15

${ }_{5}^{5}$ Bayyinatul Muchtaromah,Pendidikan Reproduksi Bagi Anak Menuju Aqil Baliq, (Malang: UIN Malang Press, 2008) hlm
} 
kekerasan seksual terhadap anak dengan memperkenalkan pendidikan seks kepada anak usia dini.

Pendidikan seks untuk AUD bukan mengajarkan anak untuk melakukan seks bebas ketika mereka dewasa kelak. Pendidikan yang dimaksud agar anak memahami akan kondisi tubuhnya, kondisi tubuh lawan jenisnya, serta menjaga dan menghindarkan anak dari kekerasan seksual. Pahamkan anak tentang tubuh beserta fungsinya dan dampingi mereka dalam menghadapi perubahan fisiknya dengan berbagai penjelasan yang berlandaskan norma agama. Sehingga anak lebih menjiwai bahwa mereka terlahir disertai dengan pengembangan tanggung jawab. Setiap apa yang mereka lakukan, kelak akan dimintai pertanggung jawaban dari Allah SWT. ${ }^{6}$

Menurut Sigmund Freud fase perkembangan psikoseksual terbagi beberapa fase. Fase tersebut adalah fase oral (0-1) tahun pada fase ini anak memperoleh kepuasan aktivitas mulutnya, Fase Anal (1-3) tahun pada fase ini anak memperoleh kepuasan dari aktivitas yang cenderung pada masa pertumbuhan, fase falis (3-5) tahun fase ini anak sudah mulai mengenal perbedan jenis kelamin miliknya dan milik lawan jenisnya. $^{7}$

Peneliti ingin melakukan penelitian di TK Islam Plus (TKIP) Mutiara Baturetno Bantul, karena TKIP Mutiara ini memiliki keunikan, yaitu di waktu jam istirahat sudah selesai, para guru membuat lingkaran diskusi dan bertanya tentang kegiatan di jam istirahat seperti bermain dan bertemu dengan siapa. Toilet putra dan putri yang sudah dipisahkan, dan panggilan guru dengan menyebut putra dan putri. Di TK Islam Plus Mutiara sudah sedikit diterapkan dan dibiasakan pendidikan seks. Berdasarkan hal diatas, maka penulis tertarik untuk melakukan studi deskriptif Kualitatif dalam melakukan penelitian ini yang berjudul "Model Pendidikan Seks Pada Anak di TK Islam Plus Mutiara Baturetno Bantul Yogyakarta" Mengacu pada permasalahan di atas, maka pemecahan masalah yang akan diungkapkan dari tulisan ini adalah: 1) Bagaimana model pendidikan seks pada anak di TKIP Mutiara Baturetno Bantul

\footnotetext{
${ }^{6}$ Nurul Chomaria ,Pendidikan Seks Untuk Anak Dari Balita hingga dewasa (Solo: Aqwam,2012 ) hlm 10

${ }^{7}$ Sumadi Suryabroto, ,Psikologi Kepribadian, (Jakarta: PT Raja Grafindo Persada,1966) hlm 150
} 
Yogyakarta?, 2) Mengapa perlu pendidikan seks pada anak di TKIP Mutiara Baturetno Bantul Yogyakarta?

\section{B. METODE PENELITIAN}

Penelitian ini adalah penelitian lapangan (field research), yaitu penelitian yang mengumpulkan datanya dilakukan di lapangan dengan mengamati, menganalisis dan menyajikan fakta secara sistematik tentang keadaan objek penelitian. Sifat penelitian ini adalah deskriptif kualitatif yaitu penelitian yang bertujuan menggambarkan secara sistematis mengenai fakta-fakta yang ditemukan dilapangan bersifat verbal, kalimat, fenomena-fenomena dan tidak berupa angka. Pendekatan penelitian yang digunakan dalam penelitian ini adalah pendekatan fenomenologi. Pendekatan fenomenologis sering digunakan sebagai anggapan umum untuk menunjukkan pada pengalaman subyektif dari berbagai jenis type subyek yang ditemui. Subyek penelitian atau informan adalah: Kepala sekolah, guru dan wali murid TKIP Mutiara Baturetno Bantul Yogyakarta. Sedangkan objeknya adalah anak-anak di TKIP Mutiara Baturetno. Adapun data yang akan digali dari subyek penelitian ini terdiri dari kata utama yang berupa kata-kata dan tindakan (primer), dan data tambahan yang berupa dokumen-dokumen (sekunder). Sehingga beberapa sumber data yang dimanfaatkan dalam penelitian ini meliputi data primer dan sekunder. Data dalam penelitian dikumpulkan dengan menggunakan teknik observasi, wawancara, dan dokumentasi.

\section{HASIL PENELITIAN}

\section{a. Model Pendidikan Seks}

Menurut Joyce dan Weil dari kutipan Rusman berpendapat bahwa model pembelajaran adalah suatu rencana atau pola yang dapat digunakan untuk membentuk kurikulum (rencana pembelajaran Jangka panjang), merancang bahan-bahan pembelajaran, dan membimbing pembelajaran dikelas atau yang lain. ${ }^{8}$

\footnotetext{
${ }^{8}$ Rusman, Model Model Pembelajaran Mengembangkan Profesionalisme Guru Edisi kedua,Cet Ke-6 (Jakarta: Rajawali Press,2013) hlm 132
} 
Model pembelajaran tidak langsung merupakan Model pembelajaran yang tanpa mengguru. Peran guru dalam model pembelajaran ini adalah sebagai fasilitator. Oleh karena itu, guru hendaknya mempunyai hubungan pribadi yang positif dengan siswanya, yaitu sebagai pembimbing bagi pertumbuhan dan perkembangannya dalam menjalankan perannya. ${ }^{9}$

Dari hasil penelitian, Peneliti dapat menyimpulkan bahwa dalam Model pembelajaran langsung, guru hanya bertindak sebagai fasilitator untuk peserta didiknya. Adapun teknik yang digunakkan di TKIP Mutiara jika dilihat dalam model pembelajaran menurut Roger lebih ke tahap pertama dan ke tiga, yakni membantu siswa menemukan inti permasalahan yang dihadapinnya dan membantu siswa secara bertahap mengembangkan pemahaman (kesadaran) akan dirinya. Model tidak langsung adalah Model pembelajaran tanpa mengguru.

"Saya menggunakan pendekatan individu bila menerapkan materi pendidikan seksualitas ke anak atau peserta didik. Melakukan pendekatan secara pribadi. Karena dengan cara itu sedikit pendidikan seks dalam pembiasaan punya program toilet training bisa dilakukan. ${ }^{10}$

Hasil wawancara dengan ibu Yessi, peneliti menyimpulkan bahwa dalam menerapkan pendidikan seks bagi anak khususnya dalam program toilet training memerlukan pendekatan individu dan pembiasaan. Namun, dalam hal ini disamping ada pendekatan perlu adanya pembiasaan untuk peserta didik.

Pendekatan individu adalah upaya membantu siswa untuk mengembangkan hubungan yang produktif dengan lingkungan dan membantu sebagai pribadi yang mampu/berguna. ${ }^{11}$

Selanjutnya Pembiasaan adalah proses dimana kita menghentikan pemberian atau penanggapan stimulus yang di ulang terus menerus. Namun, terdapat perbedaan individual dalam pembiasaan. ${ }^{12}$

\footnotetext{
${ }^{9}$ Hamzah, Model Pembelajaran Menciptakan Proses Belajar Mengajar yang Kreatif dan Efektif Cet Ke- 7 ,(Jakarta: Bumi Aksara, 2011) hlm 18

${ }^{10}$ Hasil wawancara kepada ibu Yessy selaku guru Tk, di kelas sentra Imtaq, pada tanggal

${ }^{11}$ Rusman, Model Model Pembelajaran Mengembangkan Profesionalisme Guru Edisi kedua,Cet Ke-6 (Jakarta: Rajawali Press,2013) hlm 132
} 


\section{b. Tujuan Pendidikan Seks di TKIP Mutiara}

Fenomena kekerasan seksual anak usia dini (0-6 tahun) di Indonesia saat ini semakin marak diberikan di berbagai media. Anak usia dini termasuk kelompok yang sangat rentan akan kekerasan seksual atau aktivitas seksual.

Lingkungan di sekitar anak usia dini memiliki peran untuk mencegah kekerasan seksual yang dapat terjadi. Salah satunya dengan membekali anak pengetahuan, nilainilai, sikap, dan keterampilan yang berhubungan dengan anatomi tubuh, hubungan personal dan seksualitas atau memberikan pendidikan seksualitas pada anak sejak dini.

Terkait dengan pendidikan seks ini mestinya menjadi tanggung jawab orangtua dirumah. Jika orang tua mampu membangun komunikasi yang baik dengan anakanaknya, membangun sikap keterbukaan, keakraban dalam suasana penuh hormat, maka persoalan-persoalan anak terkait dengan seks dapat ditanyakan kepada orangtuanya.

Anak-anak termasuk kelompok yang sulit untuk terdeteksi, karena tidak semua anak-anak memahami serta mengungkapkan kekerasan seksual pada dirinya.oleh karena itu peran guru disekolah sangat penting. Melihat fakta sekarang bahwa anakanak sekarang lebih kritis dan berani mengekspresikan sesuatu. Salah satunya yang berkaitan dengan pertemanan dengan lawan jenis. Salah satu cara untuk mengatasi permasalahan seksual pada anak adalah memberikan pendidikan seksual secara tepat sejak dini.

\section{c. Pandangan pendidikan seks di TKIP Mutiara}

Keterbatasan orangtua dalam memberikan pendidikan seks pada anak-anaknya. Bahwa memang banyak orangtua yang masih malu dan menganggap tabu untuk berbicara tentang seks, sehingga pendidikan seks perlu dilakukan oleh pihak sekolah. Sebagaimana hasil peneliti wawancara dengan bapak saiful Haq, M.Pd

${ }^{12}$ Bayyinatul Muchtaromah,Pendidikan Reproduksi Bagi Anak Menuju Aqil Baliq, (Malang: UIN Malang Press, 2008) hlm 
"Bagaimana kita bisa memberikan pendidikan seks pada anak secara dini, jika beberapa orangtua masih menggapa tabu tentang sex. Sex mempunyai sisi pengertian yang berbeda-beda, yakni tentang jenis kelamin dan hubungan kelamin. Tetapi pendidikan seks untuk anak yaitu untuk mengenal jenis kelamin, dan pendidikan seks bagi anak dilakukan sejak anak umur 0 tahun atau 3 tahun”.

Hasil wawancara tersebut, peneliti dapat menyimpulkan bahwa pendidikan seks untuk anak bagi beberapa orang tua masih dianggap tabu. Pendidikan seks sebagai hak ekslusif. Sebagian orang tua seolah masih ragu berbicara kepada anak tentang seks. Karena dipandang tidak etis atau tidak pantas. Padahal justru ditangan orang tua dasar-dasar pendidikan seks itu harus ada ditanamkan sejak awal sehingga anak tidak perlu mencari informasi seks yang salah karena diperoleh bukan dari sumber semestinya.

\section{d. Kebijakan Pendidikan Seks di TKIP Mutiara}

Kebijakan ini untuk mempersiapkan anak untuk melewati Pendidikan seks pada anak adalah melewati tahapan perkembangan seksual anak secara optimal. Sebagaimana hasil wawancara dengan kepala Sekolah bapak saiful Haq di TKIP Mutiara adalah sebagai berikut:

“Kebijakan yang kami ambil sesuai dengan Permendikbud no 146 tahun 2104 pasal 1. Bahwa pendidikan bagi anak usia dini memiliki perhatian mendasar. Dan sekarang banyak pelecehan seksual anak yang menjadi hal yang sangat perlu diperhatikan". 13

Peremendikbud No 146 tahun 2014 pasal 1 tentang kurikulum 2013 pendidikan anak usia dini pasal 1:

"Pendidikan Anka Usia Dini, yang selanjutnya disingkat PAUD, merupakan suatu upaya pembinaan yang ditunjukan kepada anak sejak lahir sampai dengan usia 6 (tahun) yang dilakukan melalui pemberian rangsangan pendidikan untuk membantu pertumbuhan dan perkembangan jasmani dan rohani agar anak memiliki kesiapan dalam memasuki pendidikan lebih lanjut." 14

Wawancara kepada ibu Erni guru TK tentang memilihnya toilet sebagai program pendidikan seks di TKIP Mutiara sebagai berikut:

\footnotetext{
${ }^{13}$ Hasil wawancara peneliti terhadap bapak saiful Haq, pada hari senin tanggal 19 Maret 2018 pukul 08.45 WIB

${ }^{14}$ Permendikbud, dalam http://paud.Kemdikbud.go.id. Akses tanggal 3 Mei 2018.
} 
"Kenapa memilih program toilet, menurut saya, karena sejatinya manusia dalam kehidupan sehari-hari tidak lepas dari makan, minum, tidur, pipis (Buang air kecil) dan BAB. Jadi pihak sekolah sengaja memanfaat toilet ini menjadi salah satu bentuk pendidikan seks. ${ }^{15}$

Peneliti dapat menyimpulkan bahwa TKIP Mutiara, mengambil toilet sebagai pendidikan seks adalah karena kehidupan manusia tidak jauh dari namanya Makan, Minum, dan salah satunya BAK (buang Air kecil dan BAB (Buang air besar). Sehingga toilet training ini bisa dijadikan salah satu pendidikan seks.

Kemudian untuk deskripsi toilet yang dijadikan sebagai pendidikan seks pada Anak di TKIP Mutiara ada 6 (enam ) kamar mandi/ wc dengan luas $2 \mathrm{~m}^{2}$ setiap kamar mandi. Kondisi kamar mandi baik, ember dan gayung ada, kondisi lantai baik, keadaan pintu baik, keadaan cat juga baik. Letak kamar mandi juga sudah memenuhi untuk dijangkau anak-anak. ${ }^{16}$

Toilet training yang ada di TKIP Mutiara sudah dipisahkan untuk anatar laki-laki dan perempuan dengan di beri tanda di bagian tas pintu dengan tulisan Putra bagi kamar mandi putra dan Putri bagi kamar mandi putri. Dibawah ini merupakan tabel saran dan prasaran penunjang TKIP Mutiara Baturetno Bantul yogyakarta.

Tabel 1.1

\begin{tabular}{|c|c|c|c|c|}
\hline No & $\begin{array}{l}\text { Nowia Rnang } \\
\text { Penuniang lainnya }\end{array}$ & Lins & Kondis: & Keterangat \\
\hline 1. & Aula & $95 \mathrm{mil}^{2}$ & Baik & Kegatan makn \\
\hline ! & Dapuf & $6 \mathrm{~m}^{2}$ & Baik & siang \\
\hline$\hat{3}$ & Kamar matdil/wc & $2 \mathrm{~m}^{2}$ & Baik & \\
\hline 4. & Kolanrengeng & $12 \mathrm{~m}^{2}$ & Baik & Ada 6 bual \\
\hline 4 & IKS & $12 \mathrm{~m}^{2}$ & Baik & Keg Ekstra Renang \\
\hline 6 & Musidu & $12 \mathrm{ill}^{2}$ & Biak & \\
\hline$i$ & Guldang & $8 m^{2}$ & Baik & \\
\hline
\end{tabular}

${ }^{15}$ Hasil wawancara dengan ibu Erni selaku guru TK pada hari senin pada tanggal 19 Maret 2018

${ }^{16}$ Hasil observasi di TKIP Mutiara Baturetno Bantul yogyakarta, pada tanggal 19 Maret 2018, pukul 10.30 


\section{e. Kurikulum Pendidikan seks di TKIP Mutiara}

Program kurikulum di PAUD Terpadu Mutiara Baturetno Bantul Yogyakarta, menggunakan 6 aspek pengembangan yakni aspek nilai agama dan moral, aspek fisik motorik, aspek kognitif, aspek bahasa, aspek sosial emosional dan aspek seni. ${ }^{17}$

Kurikulum TKIP Mutiara sudah ada bagian-bagian atau materi tentang pendidikan seks. Hasil Observasi di kelas sentra dan Dokumentasi di TKIP Mutiara, peneliti mengambil beberapa contoh yang masuk dalam materi pendidikan seks kemudian peneliti membuat tabel yang sesuai dengan pendidikan seks.

Tabel 2.1

Kurikulum yang sesuai dengan pendidikan seks. ${ }^{18}$

\begin{tabular}{|c|c|c|}
\hline $\begin{array}{c}\text { Program } \\
\text { pengembangan }\end{array}$ & Kemampuan dasar & Keterangan \\
\hline $\begin{array}{l}\text { Nilad Agama } \\
\text { dan Moral }\end{array}$ & $\begin{array}{l}\text { Mempercayad adanya Tuhan melalud } \\
\text { ciptaan-Nya }\end{array}$ & $\begin{array}{l}\text { - Mengenalkan anggora rubuh (anak } \\
\text { menerima perbedaan anggota tubuh laki- } \\
\text { laki dan pcrcmpuan scrta fungsinya) }\end{array}$ \\
\hline Fisik Motorik & $\begin{array}{l}\text { Mengenal Anggota tubuh, fungsi, dan } \\
\text { gerakannya untuk pengembangan } \\
\text { motorik kasar dan motorik halus. } \\
\text { Mengenal linglangan sosial } \\
\text { (keluarga, teman, tempat tinggal, } \\
\text { tempat ibadah, budaya, trasportasi) } \\
\text { dan monyajikan bcrbagai karyanya } \\
\text { dalam bentuk gambar, bercerita, } \\
\text { bernyanyi, gerak tubuh, dll }\end{array}$ & $\begin{array}{l}\text { - Materi yang diberikan tentang identitas } \\
\text { diriku, ciri tubuhku, badanku } \\
\text { - Menirukan lagu gerakan anggota tubuh. } \\
\text { Memasangkan gambar fungsi anggota } \\
\text { tubuh. } \\
\text { - Mcnonton film anggota tubuh }\end{array}$ \\
\hline $\begin{array}{l}\text { Sosial } \\
\text { Emosional }\end{array}$ & $\begin{array}{l}\text { Merniliki perilaku yarly } \\
\text { mencerminkan } \quad \text { kemandirian. } \\
\text { memilik kemampuan menyesuikan } \\
\text { diri }\end{array}$ & 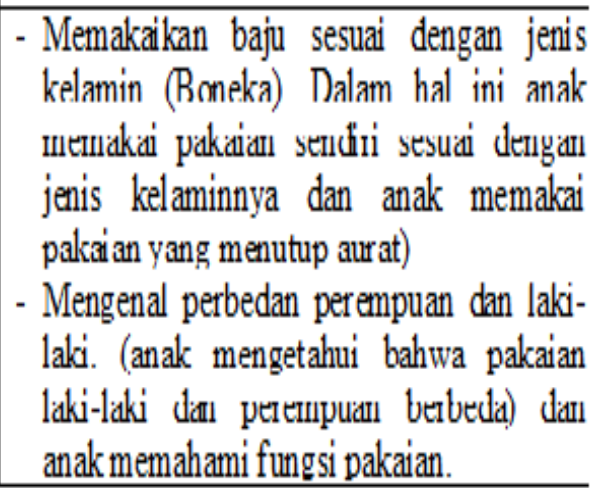 \\
\hline
\end{tabular}

${ }^{17}$ Dokumentasi kurikulum TKIP Mutiara Baturetno Bantul Yogyakarta

${ }^{18}$ Dokumentasi kurikulum TKIP Mutiara Baturetno Bantul Yogyakarta 


\section{f. Pentingnya Pendidikan Seks diterapkan menurut Pihak Sekolah}

Wawancara pertama peneliti tunjukan kepada ibu Erni guru TK Islam Plus Mutiara. Beliau memaparkan tentang pengertian pendidikan seksualitas sebagai berikut:

"Pendidikan seks untuk anak adalah memberikan pemahaman kepada anak perbedaan jenis kelaminnya. Untuk pendidikan setiap seks pada anak kan berbeda beda ya, sesuai dengan tingkatan umurnya. Untuk usia 3 tahun pembiasaan toilet trainning. ${ }^{19}$

Hasil wawancara di atas dapat ditarik kesimpulan bahwa pendidikan seks adalah pendidikan yang mengenalkan jenis kelamin atau gender pada anak dan menyesuikan tahapan-tahapan perkembangan anak untuk memberikan pendidikan seks itu sendiri khususnya pendidik dan orang tua.

Menurut Sigmund Freud fase perkembangan psikoseksual terbagi beberapa fase. Fase tersebut adalah fase oral (0-1) tahun pada fase ini anak memperoleh kepuasan aktivitas mulutnya, Fase Anal (1-3) tahun pada fase ini anak memperoleh kepuasan anak di dapat melalui aktivitas yang cenderung pada masa pertumbuhan. Ini sering di lakukan anak lama-lama di kamar mandi, fase falis (3-5) tahun fase ini anak sudah mulai mengenal perbedan jenis kelamin miliknya dan milik lawan jenisnya. ${ }^{20}$

\section{g. Pelaksanaan Pendidikan Seks untuk Anak}

\section{1) Metode Pendidikan Seks}

Metode terkadang guru harus menyesuaikan dengan kondisi dan suasana kelas. Jumlah anak mempengaruhi penggunaan metode. Tujuan instruksional adalah pedoman yang mutlak dalam pemilihan metode. Dalam mengajar juga guru jarang sekali menggunakan satu metode, karena mereka menyadari bahwa semua metode lebih cenderung menghasilkan kegiatan belajar mengajar yang membosankan bagi anak didik.

\footnotetext{
${ }^{19}$ Hasil wawancara dengan ibu Erni di TKIP Mutiara di ruang aula, pada hari senin 19 Maret 2018, pukul 08.45 WIB

${ }^{20}$ Sumadi Suryabroto, ,Psikologi Kepribadian, (Jakarta: PT Raja Grafindo Persada,1966) hlm 150
} 
Metode yang sering digunakan dalam pembelajaran TKIP Mutiara Baturetno Bantul Yogyakarta adalah metode tanya jawab, metode bercerita, bercakap-cakap, praktek langsung dan pemberian tugas. Semua saling mendukung tidak bisa berdiri sendiri. Sebelumnya anak-anak di TKIP Mutiara Baturetno sudah mendapatkan MOS (Masa Orientasi Siswa) selama satu minggu. MOS yang dimaksudkan disini adalah guru memberikan pengarahan kepada anak-anak. ruang kepala sekolah, dapur, ruang aula, kamar mandi untuk putra dan putri, serta bagian-bagaian kelas sesuai sentra.

\section{2) Materi Pendidikan Seks}

Materi pendidikan seks yang telah disajikan oleh TKIP Mutiara Baturetno sudah terencana dengan baik. Materi yang disampaikan pada anak didik harus disesuaikan dengan usia pertumbuhan dan perkembangan anak, agar tujuan pembelajaran dapat tercapai sesuai dengan yang diharapkan oleh guru.

Materi Pendidikan seks di TKIP Mutiara Baturetno yang digunakan dalam pembelajaran adalah Mempercayai Manusia ciptaan Allah, mengenal anggota Tubuh, dengan tema Diri Sendiri dan sub temanya Identitas Diri. Adapun tujuan pembelajaranya adalah: ${ }^{21}$

a. Anak mengetahui bahwa manusia tubuh ciptaan Allah

b. Anak memilik sikap ingin tahu namanya

c. Alamat rumahnya, ciri tubuhnya, keluarganya dan rumahnya.

d. Anak mampu bersikap kreatif menggambarkan rumahnya, alamat rumahnya.

e. Anak mampu percaya diri menyebut namanya, alamat rumah, ciri tubuhnya, keluarganya dan rumahnya.

f. Anak mampu mengenal ciri tubuhnya. Anak menjaga kelenturan untuk bermain dengan tubuhnya.

g. Anak mampu mengenal ciri tubuhnya, rumahnya.

\footnotetext{
${ }^{21}$ Dokumentasi kurikulum dan RPPM di TKIP Mutiara Baturetno Bantul Yogyakarta
} 


\section{3) Strategi dan Tehnik Pendidikan Seks}

Salah satu untuk mencapai model pendidikan seksualitas pada anak di TKIP Mutiara adalah diperlukannya pendekatan, metode, strategi dan Tehnik yang tepat adalah dengan pembiasaan. Pembiasaan yang terus dilakukan oleh pendidik kepada peserta didik. Tanpa pembiasaan semua tidak akan terwujud sesuai dengan tujuan pembelajaran. Pembiasaan di sekolah dan di luar sekolah juga akan mempengaruhi peserta didik.

Proses toilet trainning perlu kesabaran dan pembiasaan. Tingkat usia mempengaruhi proses ini, dalam melakukan proses toilet training ini kesiapan fisik dan psikis mempengaruhi. Karena toilet training itu sendiri adalah cara untuk melatih anak agar bisa mengontrol buang air kecil (BAK) dan buang air besar (BAB). Sesuai dengan usia paud, usia 1-3 sudah bisa dilakukan untuk ke toilet training

Wawancara dengan bapak saiful Haq, tentang program toilet training di TKIP Mutiara sebagai berikut:

"Untuk di luar pembelajaran, dalam pendidikan seks kami menerapkan program toilet training dengan membedakan toilet perempuan dan laki-laki disendirikan. Pembiasaan panggilan putra dan putri. Kamar ganti khusus laki-laki dan perempuan juga sudah ada sendiri-sendiri”.

Toilet Training pada dasarnya merupakan proses melatih dan menanamkan kebiasaan pada anak untuk melakukan aktivitas buang air kecil dan besar pada tempatny, di toilet. Toilet Training menjadi awal dari proses anak menuju kemandirian, dimana anak mulai belajar melakukan hal-hal kecil sendiri. Namun untuk mengajarkan kebersihan kepada anak atau peserta didik dengan melakukan BAK dan BAB pada tempatnya, bukanlah proses yang mudah dan membutuhkan waktu yang tidak sedikit. Diperlukannya pembiasaan untuk mewujudkannya.

Strategi dan tehnik yang sudah digunakan dan diterapkan di TK islam plus Mutiara Baturetno dalam pendidikan seks, adalah 
a) Metode pendidikan seks yang digunakan yakni menggunakan metode bermain peran aktif, metode bercerita, dan tanya jawab. Dan yang lebih sering digunakan adalah metode bermain peran.

b) TKIP Mutiara menyesuikan pendidikan seksualitas pada anak dengan 6 aspek perkembangan dalam setiap sentra. Pada setiap sentra telah disesauikan dengan program kurikulum TKIP Mutiara Baturetno.

c) Sekolah TKIP telah membuat program toilet training. Toilet ini sudah didesain untuk laki-laki dan perempuan dipisah, dengan diberi tanda nama di bagian atas pintu toilet tersebut.

d) Di saat jam istirahat mulai selesai. Setiap guru mencoba anak membuat lingkaran kecil, kemudian guru menanyakan satu persatu anak didiknya. Setelah usai jam istirahat

e) Pendidik membiasakan panggilan putra dan putri kepada peserta didik untuk memberi pemahaman tentang identitas diri peserta didik tersebut. Pembiasaan ini dilakukan saat baris berbaris atau sholat berjama'ah.

f) Lingkungan sekolah yang sudah terkondisikan dengan pakaian yang muslim dan muslimah. Perempuan memakai jilbab, sedangkan laki-laki tidak memakai jilbab.

\section{KESIMPULAN}

Model pendidikan seks pada anak di TKIP Mutiara Baturetno Bantul Yogyakarta yang digunakan adalah dengan menggunaka model pembelajaran tidak langsung (nondirect) yaitu suatu model untuk guru ke peserta didik tanpa menggurui. Tehnik yang digunakan yakni tehnik wawancara. Kemudian dalam pendekatannya ke pada peserta didik menggunakan pendekatan individu atau pembiasaan.

Keunggulan Sekolah TKIP Mutiara adalah dengan setting toiletnya. Toilet putra dan putri dibedakan (toilet Training). Pembiasaan panggilan putra dan putri, kamar ganti khusus putra dan putri. Materi yang digunakan dalam pendidikan seks belum ke 
materi khusus. Akan tetapi materi yang sudah diterapkan seperti lagu tentang sentuhan boleh dan tidak boleh.

Pelaksanaan proses pendidikan seks yang diajarkkan sudah terlaksana dengan baik. Pelaksanaan pembelajaran di sesuaikan dengan 6 aspek perkembangan anak. Metode yang digunakan dalam pembelajaran juga beraneka ragam contohnya bercerita, diskusi atau tanya jawab, pembiasaan, nasehat, perumpamaan dan keteladana. Materi yang yang sudah diterapkan meliputi lagu sentuhan boleh dan tidak boleh, penayangan film tentang Anggota Tubuh. Kemudian strategi yang digunakan tidak luput dari pembiasaan yang dilakukan oleh pendidik.

\section{E. DAFTAR PUSTAKA}

Anggraini, Trinita, Pendidikan Seks Untuk Anak Usia 4-5 Tahun Di Paud IT Qurrota A'yun Kota Bandar Lampung, Skripsi: Universitas

Breuner,Cora C,Gerri Mattson,Commitee on Adolescence, "Sexuality Education for Chilidren and Adolescents" dalam jurnal Pediatrics from the American Academy of Pediatrics, Vol 138, Number 2

Chomaria, Nurul, Pendidikan Seks untuk Anak Dari Balita Hingga Dewasa, Solo: Aqwam,2012.

Finkelhor, David, "The Prevention of Chilhood Sexual Abuse", dalam jurnal Future of Chilidren, Director of the Crimes againts Chilidren research center and Professor of sociologi at the University of New Hampshire. Vol.19/ No.2/FALL 2009.

Harianti ,rini,Pendidkan Seks Usia Dini,Teori dan Aplikasi, Yogyakarta: Trans medika, 2016.

Hapsari, Iriani Indri, Psikologi Perkembangan Anak, (Jakarta:Indeks, 2016)

Henny Puji Astuti, Pendidikan seksual pada anak Usia Dini, Proceeding Seminar Nasional "Selamatkan Generasi Bangsa dengan Membentuk Karakter Berbasis Kearifan Lokal

Jatmikowati,Tri Endang. Model Dan Materi Pendidikan Seks Anak Usia Dini Perspektif Untuk Menghindarkan sexual Abuse. Jurnal Cakrawala pendidikan Oktober 2015, Th. XXXIV, No.3 FKIP Universitas Muhammadiyah Jember

Madani, Yusuf Pendidikan seks dalam Islam:Panduan bagi Orang Tua, Ulama, Guru dan Kalangan lainnya (Irwan kurniawan.Terjemahan), Jakarta: Pustaka Zahra,2003 
Magdalena,Merry,Melindungi Anak Dari Seks, Jakarta: PT Gransido, 2010

Martini, Imam Mawardi, "Implementasi Metode Pendidikan Seks Untuk Anak Dalam Keluarga (Perspektif Pendidikan Islam)“,dalam Jurnal Tarbiyatuna, Vol. 8 No. 1 Juni, 2017.

Muhtadi, Muhammad, yang berjudul Panduan Lengkap Tarbiyatul Aulad: Strategi mendidik Anak Menurut Petunjuk Al-Quran dan As-Sunnah, Karya Dr. Sa'id bin Ali bin Wahf Al-Qahthani, Solo:Zamzam, 2013

Nurhasana, Wini,Implementasi Pendidikan Seksual untuk Anak Usia Dini.Skripsi, Bandung: Universitas Pendidikan Indonesia.

Listi Wuryani, Sri, pendidikan Seks Keluarga,Jakarta: PT Indeks,2008)

Rahman Hakim, Arif. Yang berjudul Pendidikan Anak Dalam Islam, , karya Dr. Abdullah Nasih Ulwan, Tahqiq: Syaikh Ihsan Al-'Utabi, Solo:Al-Andalus,2015

Roqib, Moh, "Pendidikan seks pada Anak Usia Dini”, dalam Jurnal Pemikiran Alternatif Pendidikan, P3M STAIN Purwokerto, Vol. 13, Nomor 2, Mei 2008.

Santrock, John W,Perkembangan Anak, Jilid 1 Edisi Kesebelas. Jakarta: Erlangga.2007

Septiawan ,Muhammad Haris. "Pengaruh Pendidikan Seks Dalam Keluarga Terhadap Perkembangan Moral Anak”, dalam Jurnal Kultur Demokrasi, FKIP Unila. Vol. 2, No.8 2014

Sugiono,Metode Penelitian Pendidikan:Pendekatan Kuantitatif,Kualitatif, dan RnD, Bandung: Alfabeta,2017. Cet Ke-25

Risa Fitri Ratnasari dan M.Alias "Pentingnya Pendidikan Seks Untuk Anak Usia Dini” dalam Jurnal Tarbawi Khatulistiwa. Vol.2 Nomor 2 2016, ISSN:2442756X.

Wakhidah, Rohmatul , Tesis, Perlindungan anak terhadap tindak kekerasan dalam dunia pendidikan di sekolah perspektif pendidikan Islam. (Yogyakarta:UIN Sunan Kalijaga,2017)

Zakiyah, Ratna,Persepsi orang tua Terhadap Pendidikan Seks Dini Pada Anak di Kota Dumai, Yogyakarta: Universitas Gadjah Mada 